\title{
Violación de la prohibición de discriminación en el tratamiento de la prostitución por parte de los tribunales laborales españoles*
}

\author{
Violation of the prohibition of non-discrimination by Spanish labour \\ courts when dealing with prostitution
}

\author{
Fernando Fita Ortega \\ Universidad de Valencia \\ Fernando.Fita@uv.es \\ ORCID [0000-0001-5462-6859]
}

\section{Resumen}

El reconocimiento pleno de derechos laborales a toda manifestación del trabajo sexual, incluida la prostitución, resulta plenamente necesario para la tutela no discriminatoria de las personas que, por necesidades económicas, decidan ejercer libremente la prostitución. Los tribunales laborales españoles no responden, en este punto, a la lógica tuitiva del derecho del trabajo e ignoran la vulnerabilidad a la que dejan expuestas a las trabajadoras sexuales. Aplican para ello criterios que no siempre son estrictamente jurídicos, efectuando conclusiones voluntaristas que predeterminan el contenido de sus fallos sin tomar en consideración el derecho vigente. Se produce como consecuencia de ello una discriminación de un colectivo perseguido históricamente, como el de las prostitutas, sin que exista una motivación objetiva y razonable que lo justifique. Ni la protección de la mujer como colectivo -en términos de igualdad de género-; ni la superación de las "molestias" que, para la sociedad, acompañan al ejercicio de la prostitución; ni la lucha contra la trata de personas; ni una pretendida defensa de la dignidad de las prostitutas -a quienes, paradójicamente, se priva de la misma al tratarlas como menores-; la persecución de ninguno de estos objetivos supera el juicio de proporcionalidad (idoneidad, necesidad y proporcionalidad en sentido estricto)

* Trabajo realizado en el marco del I+D de Generación del Conocimiento sobre Violencia, Trabajo y Género (VITRAGE), Ref. PGC2018-094912-B-100, del Programa Estatal de Generación de Conocimiento y fortalecimiento científico y tecnológico del sistema de I+D+i del Ministerio de Ciencia, Innovación e Universidades. 
al que deben someterse los tratos desiguales, menos todavía cuando, teniendo los derechos humanos un alcance universal, no se reconoce que las prostitutas puedan ser titulares de los mismos.

Palabras clave: Trabajo sexual, prostitución, derechos laborales, libertad sindical, no discriminación.

\begin{abstract}
The right not to suffer discrimination requires that people who choose to engage in sex work in order to meet their economic needs receive full recognition of their employment and labour rights. This includes prostitution. In this field, however, Spanish labour courts do not adhere to the protective spirit of Labour Law. Instead, they add to the vulnerability of prostitutes by denying them protection. To this end, they apply criteria that are not always strictly legal, relying on wilful arguments that often disregard the law. The result is the discrimination of prostitutes, a collective historically subject to persecution, as no reasonable argument is provided to justify their pejorative differential treatment. The protection of women as a whole -in terms of gender equality-; the need to overcome the social "nuisances" prostitution causes; the need to fight against human trafficking; the alleged desire to defend prostitutes' dignity -while paradoxically harming it, as prostitutes are treated as minors-; appealing to these aims, and depriving prostitutes of rights as a means to reach them, does not pass the proportionality test (suitability, necessity and balancing tests) unequal treatment must meet to be considered non-discriminatory. The underlying consideration is that, despite human rights' universal character, prostitutes cannot be regarded as their holders.
\end{abstract}

Key words: Sex work, prostitution, employment and labour rights, freedom of association, nondiscrimination. 


\section{La prostitución como una manifestación más del trabajo sexual}

Con carácter previo al desarrollo de las consideraciones que se efectúan en este texto, conviene realizar alguna precisión terminológica que ayude a enmarcar el texto, en concreto en torno al concepto de trabajo sexual. Sin que exista una definición recogida por la Real Academia de la lengua de lo que deba entenderse por trabajo (o trabajadora ${ }^{1}$ ) sexual, este término se identifica, normalmente, con la prostitución. Así, por ejemplo, en la aproximación terminológica que ofrece el Ministerio de Sanidad, Consumo y Bienestar Social, en su página sobre el SIDA², se hace referencia a los términos "trabajador sexual y profesional del sexo como término alternativo a los de persona que ejerce la prostitución, prostituta o persona prostituida"3.

Frente a esta realidad, el diccionario Larousse contiene, en la entrada travailleur, travailleuse, una referencia a las trabajadoras del sexo más amplia y ajustada a la realidad. De este modo, se indica: "Travailleur, travailleuse du sexe (anglais sex worker), prostitué(e); par extension, toute personne travaillant dans l'industrie du sexe (cinéma pornographique, spectacle érotique, téléphonie rose, etc.). L'expression est surtout employée par les partisans de la reconnaissance des prostitué(e)s en tant que travailleurs devant, à ce titre, bénéficier des mêmes droits et des mêmes garanties sociales que les autres."

La visión reduccionista del trabajo sexual, limitándolo a la prostitución, ignora la realidad, en una tendencia invisibilizadora del trabajo sexual que constituye una constante en su tratamiento. En efecto, el trabajo sexual va más allá de la prostitución, que no es más que una manifestación de aquel concepto, abarcando el trabajo sexual una realidad más amplia que la integrada por la prostitución, que según el diccionario de la R.A.E. es "la actividad de quien mantiene relaciones sexuales con otras personas a cambio de dinero"4. La prostitución es, pues, trabajo sexual, pero no es la única actividad que abarca el trabajo sexual. El cine y la fotografía pornográfica ${ }^{5}$-no así la

\footnotetext{
${ }^{1}$ En el texto se va a hablar siempre en femenino respecto de la persona que ejerce el trabajo sexual con objeto de respetar la realidad acerca de la feminización de esta actividad, lo que no supone, en ningún caso, ignorar que varones o personas que no responden a la realidad impuesta de un género binario trabajen igualmente desarrollando este tipo de actividad

${ }^{2}$ Lo que, por otra parte, pone en evidencia la presión estigmatizante que existe sobre el trabajo sexual, al reforzar, de modo implícito, la acusación de que es la prostitución, y no la falta de medidas de protección en las relaciones sexuales, una de las culpables de la expansión de la enfermedad. Este hecho resulta más paradójico si tenemos en cuenta que el mismo Ministerio reconoce que, a diferencia de lo que ha ocurrido en otros países, en España la prostitución no parece haber desempeñado un papel importante en la transmisión de la epidemia.

https://www.mscbs.gob.es/ciudadanos/enfLesiones/enfTransmisibles/sida/prevencion/prostitucion/docs/2005presen tacion.pdf (consultado el 27 de mayo de 2020)

${ }^{3}$ https://www.mscbs.gob.es/ciudadanos/enfLesiones/enfTransmisibles/sida/prevencion/prostitucion/elemClaveDesar Prog2005.htm (terminología y conceptos de prostitución) (consultado el 27 de mayo de 2020)

${ }^{4}$ Quedan, por consiguiente, fuera del concepto de prostitución el intercambio de favores sexuales a cambio de otras contraprestaciones no dinerarias (como puede ser la promoción política o profesional) o de las relaciones más complejas en las que el intercambio de favores es de tracto sucesivo, e incluyen no solamente los de carácter sexual, sino también de cuidado, y, por la contraparte, no una retribución puntual por cada servicio de carácter sexual, sino una compensación en forma de aseguramiento de un bienestar y seguridad económica. El lucro perseguido por la trabajadora sexual es un lucro de naturaleza exclusivamente pecuniaria.

${ }^{5}$ Concepto éste que tampoco es pacífico. Al respecto, Seña (1992).
}

Revista del Laboratorio Iberoamericano para el Estudio Sociohistórico de las Sexualidades


novela o poesía pornográfica ${ }^{6}$-, los teléfonos y espectáculos eróticos (striptease, go-go dancers, lap dancers, burlesque, peep-shows, pole dancing...), las web-cam de contenido sexual, etc., son todas actividades de carácter sexual que no implican necesariamente el mantenimiento de una relación física.

En todo caso, debe advertirse que, para ser considerado trabajo, esto es, una actividad desarrollada a cambio de una contraprestación económica, es requisito indispensable la aceptación voluntaria del mismo mediante el consentimiento válidamente prestado (sin error, dolo, violencia o intimidación ${ }^{7}$ ) por la trabajadora sexual, requiriéndose que dicho consentimiento sea formalmente válido, con independencia de las circunstancias que hayan conducido a otorgarlo válidamente. Así pues, la voluntariedad a que se hace referencia supone una voluntariedad formal y no material, obviándose la consideración de que el trabajo supone para el trabajador su único medio de subsistencia y, por tanto, desde este punto de vista, no resultaría voluntario, sino necesario ${ }^{8}$. Tal y como se ha dicho con relación al trabajo dependiente y por cuenta ajena, propio del derecho del trabajo, pero predicable respecto de todo tipo de contrato, "la voluntariedad del trabajo equivale a la facultad de decidir sobre su realización sin la presencia de una fuerza inmediata que obligue a ella, y de cuya inobservancia se derive para el sujeto un mal directo de carácter económico o incluso físico" (De la Villa, 1969, p. 111). Toda referencia efectuada a la prostitución en este texto se debe entender efectuada, salvo cuando se señale lo contrario, con relación a la prostitución voluntaria, como manifestación de la libertad del individuo.

La referencia a la voluntariedad, como elemento consustancial a todo acuerdo de voluntades, supone, por consiguiente, la libre aceptación del trabajo, o si se prefiere, la libre celebración del contrato en cuya virtud surge el deber de prestar un trabajo. Es por ello que, en ocasiones, se ha hablado de trabajo libre ${ }^{9}$ en lugar de trabajo voluntario.

\section{El bien jurídico objeto de tutela en el tratamiento legal de la prostitución}

En el debate acerca del tratamiento jurídico que debe darse a la prostitución, la primera de las consideraciones a efectuar se refiere al bien jurídico que dicha regulación debe proteger. Desde mi punto de vista, son cuatro las opciones que se han planteado en dicho debate, identificando como bienes objeto de tutela: a) las mujeres, como colectivo, al considerar el fenómeno de la prostitución desde una perspectiva de género ${ }^{10}$; b) la sociedad, en su conjunto, dado que la prostitución, que resulta en numerosas ocasiones considerada en sí misma como un mal, viene rodeada de otros males, como la inseguridad, la pérdida de valor inmobiliario de los barrios en los que se ejerce, la depravación moral que -se dice- supone, la salud pública o la afectación en el crecimiento personal de los menores cuando se ejerce a la vista de todos; c) las víctimas de trata; d) la persona que ejerce la prostitución, ya sea con objeto de proteger su dignidad ${ }^{11}$, o la situación de vulnerabilidad que la prostituta presenta en el ejercicio de su actividad.

\footnotetext{
${ }^{6}$ Pese a que etimológicamente el término se refiera a la escritura (grafia) relativa a la prostitución (porneia) [Nubiola y Bernal, 1992, p. 263], el trabajo sexual implica un trabajo corporal.

${ }^{7}$ Artículo 1.265 C.C.

${ }^{8}$ El consentimiento, pues, hace referencia a la capacidad de negociación, que se encuentra en mayor presencia en la prostitución que en las relaciones sexuales sin contraprestación económica a cambio (Perera, 2019, p. 8)

${ }^{9}$ Así, con relación a trabajo por cuenta ajena, entre otros, Alonso Olea, 1971, p. 152.

${ }^{10}$ Es la perspectiva con la que dice que se debe afrontar la prostitución el "Documento de feminismos. Una transición feminista". Equipo de Pablo Iglesias. Unidas Podemos. En todo caso, añade el documento, debe abordarse "poniendo en el centro a las mujeres y, sobre todo, atendiendo a las situaciones de vulnerabilidad de las que parten".

${ }^{11}$ Ello es así puesto que la prostitución, "degradación comercializada de la íntima comunicación sexual en beneficio sobre todo de los varones" (Nubiola y Bernal, 2012, p. 263) se declara incompatible con la dignidad de la persona.
}

Revista del Laboratorio Iberoamericano para el Estudio Sociohistórico de las Sexualidades https://doi.org/10.46661/relies.4975 
De estos bienes jurídicos a proteger, es el de la persona en el ejercicio de su actividad sexual el que, en todo caso, debe prevalecer, con objeto de protegerla ante su situación de vulnerabilidad. Ello es así, en primer lugar, por la necesidad de actuar en defensa de los derechos humanos de las prostitutas, tan reiteradamente ignorados en la historia de la humanidad. Lo es, en segundo lugar, porque la tutela de los restantes bienes jurídicos señalados, no resulta incompatible con la protección de la prostituta ante su situación de vulnerabilidad. Finalmente, los argumentos sobre que se sustenta alguno de los bienes jurídicos señalados resultan, simplemente, insostenibles.

Comenzando por esto último, cabe destacar que no puede argumentarse que se está actuando en defensa de la dignidad de las prostitutas privándoles de la misma, y obligándolas a someterse a los valores de la sociedad heteropatriarcal dominante. El Tribunal Constitucional, en su sentencia 53/1985, de 11 de abril, afirma que la dignidad de la persona "es un valor espiritual y moral inherente a la persona, que se manifiesta singularmente en la autodeterminación consciente y responsable de la propia vida y que lleva consigo la pretensión al respeto por parte de los demás" (FJ 8). Esta idea se reitera en la STC 192/2003, de 27 de octubre, en la que se señala que la dignidad personal del trabajador debe ser entendida como "el derecho de todas las personas a un trato que no contradiga su condición de ser racional igual y libre, capaz de determinar su conducta en relación consigo mismo y su entorno, esto es, la capacidad de autodeterminación consciente y responsable de la propia vida" (FJ 7). Como ya tuve la oportunidad de avanzar en una ocasión anterior, la dignidad -o su contrario, la indignidad- no es predicable respecto de la actividad de la prostitución, sino que estos calificativos pueden atribuirse únicamente a las condiciones en las que aquélla se ejerce (Fita Ortega, 2009).

El segundo de los motivos que lleva a concluir que el bien jurídico a tutelar, en una actuación normativa sobre la prostitución, debe ser el de la persona de la trabajadora sexual, se basa en la ausencia de incompatibilidad de éste con los restantes. Así, por lo que se refiere a la lucha contra la trata de personas, que es un fenómeno que no se dirige exclusivamente a los fines de la explotación sexual sino a los más amplios de explotación laboral, no existe contraposición entre sacar de la invisibilidad a la prostitución voluntaria y la lucha contra las redes de trata. Es más, aflorando la parte de la prostitución que no deriva de la trata quizá se pudiera combatir mejor ésta, al dejar de compartir un mismo espacio de forma indiferenciada. En cuanto a la lucha contra la desigualdad de género existente en el fenómeno de la prostitución, lo que no es sino una manifestación más de la desigualdad de genero existente en la sociedad, existen otros mecanismos, no lesivos de derechos fundamentales, que permitirían avanzar en su erradicación, como sucede con la educación.

Enlaza esta consideración con el principal argumento que conduce a defender una situación jurídica de la prostitución centrada en las necesidades de la persona que la ejerce. El bien jurídico a tutelar en una regulación normativa del fenómeno de la prostitución no puede ser otro que el de la defensa de la persona, reconociendo los derechos que históricamente le han sido negados por verse abocada a la prostitución.

\section{Prostitución y discriminación}

Las dificultades de determinación conceptual de lo que deba entenderse por discriminación frente a la igualdad de trato (Mccrudden \& Prechal, 2009) han sido resueltas, en los tribunales españoles, señalando que no siempre que existe un trato diferente nace una discriminación vedada por el ordenamiento jurídico, sino que es preciso que tal diversidad de trato tenga por motivo determinadas causas ${ }^{12}$, que en la Constitución española son: “nacimiento, raza, sexo, religión,

12 STC 34/1984, de 9 de marzo de 1984.

Revista del Laboratorio Iberoamericano para el Estudio Sociohistórico de las Sexualidades https://doi.org/10.46661/relies.4975 
opinión o cualquier otra condición o circunstancia personal o social" (artículo 14). Todos estos factores de diferenciación guardan en común la circunstancia de hacer referencia a "condiciones que históricamente han estado ligadas a formas de opresión o de segregación de determinados grupos de personas o que se excluyen como elementos de diferenciación para asegurar la plena eficacia de los valores constitucionales en que se funda la convivencia en una sociedad democrática y pluralista"13.

Teniendo en cuenta la característica que identifica las causas de diferenciación discriminatorias esto es, el hostigamiento, la opresión o la segregación-, es evidente que las personas que ejercen la prostitución han sido, y continúan siendo, un colectivo cuyo trato diferenciado supone una clara discriminación. Dicho hostigamiento, traducido en su tratamiento como elementos ordinarios molestos presentes en la sociedad, tales como las alcantarillas o los desagües y que, por tanto, es preciso invisibilizar para disminuir cualquier molestia a los sentidos (Acton, 1870, p. 3), es histórico. Así, por ejemplo, cabe referirse al hecho de que, obligadas a quedar confinadas en los burdeles para el control de la actividad y en tutela de la integridad moral de los ciudadanos, las prostitutas de la ciudad de Valencia en el siglo XIV -actividad por entonces, al igual que hoy día, tolerada por los poderes públicos cuando se ajustaba a las normas establecidas para su funcionamiento- tenían limitado su acceso a la ciudad ${ }^{14}$ en aras de proteger la integridad moral de los ciudadanos, así como la honestidad de las mujeres honradas, que, se decía, podían sentirse atraídas por el particular modo de vida de las prostitutas. Se les imponían así reglas de vestuario cuando, en situaciones excepcionales, debían visitar la ciudad, prohibiéndoseles el uso de determinadas prendas de abrigo, como las capas, pieles o adornos, para diferenciarlas "de las buenas", al tiempo que estigmatizar a las prostitutas, a quienes se designaba con términos despectivos que ponían de relieve el carácter despreciable de la actividad y de la persona que la ejercía. La prostitución, en fin, ha sido considerada, desde el punto de vista ideológico de las clases dominantes a lo largo de los siglos, una conducta desviada, de modo que la prostituta sigue un camino equivocado que es necesario corregir (Peris, 1990, pp. 188 y 196).

Identificado el colectivo de las prostitutas como posible objeto de trato discriminatorio, es preciso hacer referencia a los tratos desiguales susceptibles de ser calificados como tales. Esas diferencias de trato se detectan claramente, en la actualidad, en la falta de reconocimiento de derechos sociales vinculados al ejercicio legal de una actividad económica. Constituyendo el trabajo sexual una actividad económica tolerada, aunque en general no reconocida por los tribunales como posible objeto de un contrato de trabajo, quienes la ejercen se ven privados del beneficio consistente en los derechos sociales vinculados al trabajo dependiente y por cuenta ajena, tales como cobertura en situaciones de enfermedad o accidente -comunes o profesionales-, prestaciones por desempleo, acceso a pensiones de jubilación, así como a todo el entramado de derechos laborales reconocidos en la normativa aplicable al contrato de trabajo. Situación ésta que, por lo demás, conduce a que las reclamaciones que quieran efectuarse por las prostitutas frente a quienes organizan y dirigen su

\footnotetext{
${ }^{13}$ STS (Social) de 29 de enero de 2001 (Recud. no. 1566/2000), FD 2.

${ }^{14}$ Del mismo modo que en la actualidad se les impide o dificulta el acceso a un país, Es el caso, en UUEE, de la no admisión a quien haya vendido sexo en los 10 años anteriores (Mac \& Smith, 2018). Por otra parte, se encuentran también ejemplos de estas limitaciones en las sentencias del TJUE acerca de impedimentos a la libre circulación de personas y trabajadores y libertad de establecimiento (entre otras, STJ de 5 de marzo de 1980, asunto C-98/79, Precastaing; 18 de mayo de 1982, asuntos acumulados C-115/81 y C-116/81, Adoui; de 20 noviembre 2001, asunto C268/99, Janny y otros).
}

Revista del Laboratorio Iberoamericano para el Estudio Sociohistórico de las Sexualidades https://doi.org/10.46661/relies.4975 
actividad se reconduzcan al orden jurisdiccional civil $^{15}$, con la pérdida de la tutela que dispensa el proceso laboral a la parte débil de los contratos.

Esta diferencia de trato que padecen las trabadoras sexuales solamente resultaría admisible siempre y cuando existiese "una suficiente justificación de tal diferencia, que aparezca al mismo tiempo como fundada y razonable, de acuerdo con criterios y juicios de valor generalmente aceptados, y cuyas consecuencias no resulten, en todo caso, desproporcionadas" (STC 66/2015, de 13 de abril, FJ 3). Ahora bien, si es cierto que tanto en el caso de la igualdad de trato como en el de la discriminación es admisible la existencia de una justificación que evite el reproche jurídico, el Tribunal Constitucional exige un mayor rigor en el análisis de la justificación al trato desigual en virtud de un factor discriminatorio, "de manera que sólo pueden ser utilizadas excepcionalmente por el legislador como criterio de diferenciación jurídica, lo que implica la necesidad de usar en el juicio de legitimidad constitucional un canon mucho más estricto, así como un mayor rigor respecto a las exigencias materiales de proporcionalidad" (FJ 3).

En esta tesitura procede preguntarse acerca de cuál podría ser la justificación, objetiva y razonable que, guardando la debida proporcionalidad entre los medios empleados y el fin perseguido, podría admitirse para emplear el trabajo sexual -más específicamente, la prostitución- como criterio de diferenciación jurídica ${ }^{16}$. Pues bien, ni la lucha contra la desigualdad de género o la trata de personas, ni la posible evitación de los perjuicios sociales que puedan derivarse de la prostitución, pueden servir como justificación de dicho trato diferenciado, pues no superan el canon de proporcionalidad empleado por el Tribunal Constitucional ${ }^{17}$ para, ponderando los intereses en juego, estimar legítimo el trato desigual.

Así, los perjuicios sociales derivados de la prostitución pueden regularse, como se ha venido haciendo hasta la fecha, mediante disposiciones de carácter administrativo, obviamente menos lesivas de los derechos fundamentales, no superando, por consiguiente, la privación de derechos laborales el juicio de necesidad. La eliminación de la trata de personas, a través del no reconocimiento de derechos sociales a las prostitutas, es un objetivo claramente inalcanzable con esta medida, por lo que la misma no resulta idónea. Por último, la lucha por conseguir una sociedad donde se respete la igualdad de género mediante la falta de reconocimiento de derechos sociales a las prostitutas no constituye una medida proporcional en sentido estricto, al suponer un enorme sacrificio de los derechos de las personas afectadas para la consecución de un objetivo que requiere de una amplia amalgama de medidas de muy diversa índole, y cuya consecución puede demorarse prolongadamente, no resultando, pues, por sí sola, tampoco idónea para alcanzar aquél objetivo. Todo ello sin perder de vista que, en la situación actual, solamente queda vedado el reconocimiento de la prostitución como actividad laboral (no así cuando se ejerce por cuenta propia).

Por lo que se refiere a esto último, a la idoneidad de la medida para combatir la desigualdad de género, debe tenerse en cuenta que, aunque no hay datos estadísticos plenamente fiables, se admite de forma unánime e incontestada que en el colectivo de personas que ejercen la prostitución las mujeres suponen una clara mayoría, resultando una actividad claramente feminizada. De este modo, la situación de la mujer en el mercado de bienes y servicios se ve afectado por la falta del reconocimiento de derechos sociales a las prostitutas. Desde esta perspectiva, la situación podría

\footnotetext{
${ }^{15}$ Así lo sugiere la STSJ de Galicia de 10 de junio de 2002 (Recurso de Suplicación no. 1282/2002) o el voto particular de la STSJ de Cataluña de 15 mayo 2009 (Recurso de Suplicación no. 101/2008)

${ }^{16}$ Por otra parte, debe destacarse que el trato diferente de la prostitución desde una perspectiva laboral no deriva de una opción del legislador, sino de una interpretación jurisprudencial, que no reconoce a la prostitución como una realidad sobre la que cabe aplicar las reglas que disciplinan el trabajo por cuenta ajena.

${ }^{17}$ Éste impone superar el juicio de idoneidad, necesidad y proporcionalidad en sentido estricto de la medida adoptada en relación con la finalidad perseguida.
}

Revista del Laboratorio Iberoamericano para el Estudio Sociohistórico de las Sexualidades https://doi.org/10.46661/relies.4975 
analizarse como un supuesto una discriminación indirecta por razón de género, pues la prostitución, que podría entenderse como un criterio de diferenciación neutro, coloca en clara situación de desventaja a la mujer. En este sentido, Beltrán ha destacado cómo el trato diferenciado a la prostitución reúne características que permite su encaje en la consideración de trato discriminatorio, como discriminación indirecta, puesto que "la omisión del legislador en relación con muchos aspectos de esta actividad que afecta fundamentalmente a mujeres... supone la imposibilidad de ejercer derechos de ciudadanía en condiciones de igualdad con respecto a los demás ciudadanos". (Beltrán, 2011, p. 45)

Por otra parte, la discriminación no solamente se produce respecto de la prostitución frente a otras actividades, sino que se encuentra muy presente en la prostitución sin que, como consecuencia del abstencionismo legislativo que invisibiliza todo lo que se refiere a esta actividad (más allá de la trata y de las situaciones de explotación de la prostitución), permitan intervenir para erradicarla. En efecto, dentro de la prostitución pueden apreciarse diferencias de trato discriminatorias por razón de raza, de edad, o de nacionalidad, puesto que los precios de los servicios prestados, y las condiciones de trabajo, se ven afectados por todos estos factores (Pons i Antón, 1990). También la prostitución transexual resulta objeto de discriminación en algunos países ${ }^{18}$, manifestando el doble estigma que soporta la prostituta transexual, por prostituta y por transexual.

\section{El trato desigual en el reconocimiento de derechos laborales para la prostitución}

El reconocimiento de derechos a quienes desempeñan el trabajo sexual no supone otra cosa que reconocer lo innegable: las trabajadoras y los trabajadores sexuales tienen derecho a que se les reconozca la dignidad de la que injustamente han sido privadas a lo largo de la historia de la humanidad y, con ello, la recuperación de sus derechos sociales, componente esencial de los derechos humanos. Desde este punto de vista, la defensa del trabajo sexual, como un espacio regulado y con derechos, no va dirigida a tutelar los derechos de los clientes, sino que constituye una reivindicación de justicia social de quienes se dedican a esta actividad. De lo que se trata es de proporcionar herramientas para que quien desempeña el trabajo sexual de forma dependiente (bajo el círculo rector y organizativo de otra persona) tenga mayores instrumentos de negociación de sus condiciones laborales frente a su empleador, así como facilitarles los derechos que el Estado social procura a quienes prestan trabajo por cuenta ajena, de los que se ven privados las trabajadoras sexuales como consecuencia de la actual política abstencionista del legislador en torno a esta cuestión.

Porque una cosa es evidente: la situación de dependencia económica de la trabajadora sexual respecto de su trabajo la debilita enormemente en la determinación de sus condiciones de trabajo, siendo ésta la base sobre la que se asienta el derecho del trabajo. La autonomía individual de las partes solamente puede ser fuente de una relación contractual justa cuando existe un cierto equilibrio de fuerzas entre las partes negociadoras, de modo que, cuando no es así, las condiciones finales van a resultar muy probablemente draconianas para la parte contractual débil. Como afirmase Lacordaire, "entre el débil y el fuerte, entre el pobre y el rico, ... es la libertad la que oprime y es la ley la que libera" (Lacordaire, 1872).

Esta circunstancia se refleja en las diversas aproximaciones que se han efectuado al fenómeno de la prostitución, en las que se pone en evidencia que, a medida que la trabajadora sexual se aleja de un entorno en el que goza de una cierta protección (la que se deriva, en el caso de España, del hecho de que no se trata de una actividad prohibida, sino tolerada), las condiciones en las que se ejerce la

\footnotetext{
${ }^{18}$ Como, por ejemplo, en Turquía, donde las mujeres transexuales no pueden ejercer la prostitución en prostíbulos
} regentados por el Estado (Mac \& Smith, 2018).

Revista del Laboratorio Iberoamericano para el Estudio Sociohistórico de las Sexualidades https://doi.org/10.46661/relies.4975 
actividad se deterioran. Así sucede con la prostitución ejercida por inmigrantes que se hallan en situación irregular en el país donde trabajan, las cuales podrían considerarse el lumpen de la prostitución, como consecuencia de la debilidad de derechos en la que se encuentran: menores contraprestaciones, obstáculos para acceder a los servicios del Estado de bienestar, mayor posibilidad de ser objeto de abuso, agresiones, violación o violencia institucional, en pocas ocasiones denunciada por temor a las repercusiones que, para ellas mismas, pudiera conllevar la denuncia ${ }^{19}$. La falta de reconocimiento de derechos agudiza, pues, la situación de vulnerabilidad de las prostitutas 20 .

En efecto, con la privación de derechos sociales a las prostitutas, a las que se culpabiliza de ciertos grandes males de la sociedad, se las somete a un doble trato injusto. Así, para empezar, no se les ofrecen las condiciones para tener una vida digna y sin privaciones, para, posteriormente, negarles el reconocimiento a sus esfuerzos por garantizarse aquélla, incrementando su situación de privación cuando, por algún motivo (vejez, enfermedad), no pueden seguir desempeñando la actividad que les sirve de sustento, viéndose forzadas, pues, a continuar con aquella actividad en condiciones de mayor vulnerabilidad. Esta situación es incluso más dramática en el caso de aquellas mujeres que han sido, mediante engaño o violencia, objeto de trata de seres humanos con objeto de prostituirlas. Muchas de ellas, una vez liberadas de las redes que las atraparon, solamente tienen la posibilidad de continuar con su actividad sexual para garantizarse un cierto nivel de vida, así como enviar remesas económicas a sus familiares en sus países de origen. Estas personas acaban sufriendo una doble penalización, pues a la derivada de la ineficacia del Estado para evitar que hubiesen sido objeto de explotación sexual y trata se suma el posterior repudio de la actividad que ejercen para sobrevivir, lo que se traduce en la omisión de sus derechos socio-laborales.

El reconocimiento de derechos sociales a las prostitutas, como trabajadoras sexuales, se enmarca en un proyecto capaz de asegurar, de hecho, la igualdad de oportunidades para las personas, "el cual debería proponer, antes de nada, la remoción de las causas estructurales que colocan a las personas en situación de vulnerabilidad y la aproximación de esas mismas personas a las condiciones materiales que les permitirían ejercer la libertad, no solo inicialmente, sino a lo largo de todo un proceso dinámico de promoción de la igualdad". De este modo, se estaría contribuyendo a la restitución de su dignidad, "principio consustancial con el derecho de la persona a oponerse a la imposición de condiciones de vida opresivas o humillantes" (Schwarz, 2019, pp. 62, 52-53).

\subsection{La prostitución como imposible objeto de una relación laboral según los tribunales laborales españoles}

Los tribunales laborales españoles, salvo alguna puntual excepción, no reconocen la prostitución como posible objeto de una relación laboral, privando, o dificultando considerablemente, el acceso de las prostitutas a todo el entramado de derechos sociales vinculados al ejercicio de una actividad por cuenta ajena. Ello podría entenderse contrario al artículo 9.2 de la Constitución Española. En efecto, la doctrina judicial laboral mayoritaria se decanta por declarar que la prostitución no puede ser objeto del contrato de trabajo, dada la imposibilidad de someter a subordinación el favor

\footnotetext{
${ }_{19}$ Un claro ejemplo de tales repercusiones negativas ante denuncias laborales de las trabajadoras sexuales puede encontrarse en la SJS de Barcelona de 10 diciembre 2018 (Sentencia no. 363/2018, JUR\2020\106836) en la que tras declararse improcedente el despido de un varón, que bajo la denominación de "masajista" presta servicios sexuales en habitaciones de la empresa demandada, acuerda dar testimonio de la sentencia a la Inspección de Trabajo, a la vista de que tampoco al inicio de la relación de trabajo el trabajador despedido disponía de autorización administrativa para trabajar en España, por lo que podría enfrentarse a una sanción administrativa.

${ }^{20}$ Es lo que se refleja en trabajos como los de Brufao (2008); Pons i Anton (1990); Mac \& Smith (2018); o Mathieu (1999).
}

Revista del Laboratorio Iberoamericano para el Estudio Sociohistórico de las Sexualidades https://doi.org/10.46661/relies.4975 
sexual ${ }^{21}$, entendiendo ilícito el objeto del contrato en tales supuestos. Ello significa que quien ejerza esta actividad no podrá verse amparada por la tutela de las normas laborales, si bien esta circunstancia no ha evitado la posibilidad de condenar al empresario por delito contra los derechos de los trabajadores ${ }^{22}$.

Sin embargo, no han faltado ideas imaginativas para, de alguna manera, paliar esta situación, evitando así que los empleadores de las personas dedicadas a la prostitución se beneficiasen de la falta de derechos laborales de aquéllas ${ }^{23}$. Es así como aparece, a partir de la STS de 1981, de 3 de marzo, la ficticia ${ }^{24}$ diferenciación entre la actividad sexual propia de la prostitución y la de alterne por la que se procura protección de la trabajadora, cuando desempeña esta actividad mediando las notas tipificadoras de la laboralidad (Fita Ortega, 2007) frente al despido y se obliga al empresario a darles de alta y cotizar por ellas a la Seguridad Social. En este contexto, el alterne se ha venido definiendo por los tribunales laborales como una actividad feminizada y heterosexual en la que la mujer, valiéndose del atractivo sexual, incita al consumo de bebidas a los clientes varones, por lo que percibe una determinada comisión. Así se desprende, entre otras, de la STS 14 de mayo de 1985 (RJ 1985/2712) donde se afirma que la actividad de alterne consiste en "la captación de clientes varones, mediante el atractivo sexual, al objeto de que se consuman bebidas". Semejante aproximación a la definición de alterne por parte de los tribunales laborales contiene elementos discriminatorios por razón de sexo, en la medida en que solamente se refiere a la actividad prestada por mujeres para hombres, pareciendo excluir de este concepto la actividad que las mujeres puedan realizar a otras mujeres o de la que los varones puedan realizar para otras personas, sean hombres o mujeres. Por otra parte, tampoco aparecen referencias en las aproximaciones definitorias que se contienen en las sentencias a otra lucha social que viene cobrando fuerza en los últimos tiempos, como la superación del régimen sexual binario. Ciertamente, el menor número de asuntos en los que la actividad sexual deja de tener a la mujer como protagonista y al varón como receptor de los servicios, podría dar explicación a esta circunstancia.

Con relación a esta diferenciación entre alterne y prostitución, cabe hacer notar que una de las cuestiones que no aparecen directamente resueltas por la doctrina de los tribunales laborales estriba en determinar si, en los casos en los que la actividad desarrollada por la trabajadora excede de la incitación a efectuar consumiciones, entrando la actividad en el terreno de la prostitución, es dable apreciar o no una relación laboral. Esto es, se trata de decidir si es posible deslindar la actividad de alterne de la de prostitución, pudiendo reconocer la existencia de una relación laboral respecto de la primera, sin que a la misma afecte la ilicitud de la segunda actividad o si, por el contrario, la ilicitud de la actividad de prostitución subsume a la de alterne. Los Tribunales

${ }^{21}$ SAN de 23 de diciembre de 2003 (Procedimiento no. 168/2003)

${ }^{22}$ Así, desde que las SSTS (Penal) de 12 de abril de 1991 (Roj: STS 9711/1991; Roj: STS 10754/1991 y Roj STS 2035/1991) señalasen que el Código Penal "no protege las consecuencias de un contrato de trabajo formalmente válido, sino la situación de personas que prestan servicios para otra", pues "de lo contrario el más desprotegido debería cargar también con las consecuencias de su desprotección" (FD 6 en las tres sentencias), las Audiencias Provinciales han sentenciado en este mismo sentido. Así, por todas, SAP de Castellón (Sentencia no. 266/2018) de 28 septiembre (ARP\2018\1567). Esta interpretación ha sido ratificada por el Tribunal Constitucional en su sentencia 163/2004, de 4 de octubre, al constituir "una interpretación no contraria a la orientación material de la norma, que tiene en cuenta el bien jurídico protegido por la misma y los fines a los que se orienta" (FD 8).

${ }^{23}$ En algún caso se ha propuesto, con objeto de evitar la pérdida de los derechos laborales de quienes ejercen la prostitución, la aplicación del artículo 36.4 de la Ley Orgánica 4/2000, de 11 de enero, sobre derechos y libertades de los extranjeros en España y su integración social. Así se ha planteado en el voto particular de la STSJ de Andalucía de 4 de diciembre de 2003 (AS 2003/3638).

${ }^{24}$ Artificial o ficticia, se dice en la citada SJS de Barcelona de 18 de febrero de 2015 (proceso no. 835/2013), "en la medida en que la actividad de alterne no deja de ser en la mayoría de los casos meramente instrumental en orden a propiciar relaciones sexuales con los clientes" (FD 4).

Revista del Laboratorio Iberoamericano para el Estudio Sociohistórico de las Sexualidades https://doi.org/10.46661/relies.4975 
superiores de Justicia se han venido pronunciado al respecto de forma diversa, de modo que mientras para algunos no cabría deslindar ambas actividades al subsumir la ilicitud de la prostitución la actividad de "alterne" ${ }^{25}$, para otras, ambas actividades resultarían plenamente diferenciables ${ }^{26}$, llegando incluso a tomar en cuenta esta diferenciación a la hora de calcular la indemnización por despido ${ }^{27}$. Sobre este particular el Tribunal Supremo afirma que no hay, ni puede haber, contradicción, entre sentencias que se pronuncian en favor de la naturaleza jurídica laboral de la actividad de alterne, y las que por el contrario niegan la posibilidad de reconocer la existencia de una relación laboral cuando esa actividad conlleva además el ejercicio de la prostitución ${ }^{28}$. En todo caso, lo cierto es que no parece que, en la gran mayoría de las sentencias que se refieren al alterne, y lo reconocen como posible objeto de una relación laboral, se entre a valorar si junto a esta actividad se da o no la prostitución.

Por otra parte, en otros casos los tribunales valoran el carácter marginal o no de la actividad de alterne respecto del de prostitución. Así sucede en la SJS n‥ 2 de Tarragona de 20 de julio de 2007 (procedimiento no. 943/2006), que no admitió la laboralidad de la relación dado el carácter marginal o accesorio de la actividad de alterne frente al de prostitución. Esta sentencia fue revocada por la STSJ de Cataluña de 2 octubre 2008 (Recurso de Suplicación 943/2006). Igualmente, la STSJ de Cataluña de 11 noviembre 2019 (Recurso de suplicación no. 3647/2019) en la que se debate acerca de una rescisión de contrato en un supuesto de prostitución masculina voluntaria, por cuenta ajena, "enmarcada en las notas de dependencia y subordinación propias de toda relación laboral, que se realiza simultáneamente con otras actividades completamente accesorias, como son la limpieza de habitaciones y masajes, en su caso" (FD 3).

Esta última sentencia, que desautoriza la conclusión de la SJS de Barcelona de 18 de febrero de 2015 (proceso $n-$. 835/2013) -aunque no resuelve recurso alguno contra la misma-, pretende facilitar una vía alternativa al reconocimiento de la laboralidad de la prostitución con objeto de no privar a la parte más débil de un contrato de la protección que el Derecho del Trabajo le brinda. Señala el TSJ de Cataluña, en esta sentencia, que la Sala no puede compartir la declaración de la existencia de un contrato de trabajo válido como vía para dispensar la tutela de derechos, pues

\footnotetext{
el ordenamiento ya arbitra la tutela judicial efectiva y la garantía de los derechos fundamentales en el orden social por el cauce de art.177, a través de los que las personas que realizan trabajo sexual en régimen de dependencia y ajenidad pueden acudir para la tutela de sus derechos a la dignidad, libertad, igualdad e intimidad, a fin de obtener una indemnización que, siguiendo el art. 183 LRJS debe contemplar un componente disuasorio (FD 3).
}

Sorprende enormemente dicha afirmación, que pretende derivar estas reclamaciones al proceso de tutela de los derechos fundamentales y libertades públicas previsto en la Ley Reguladora de la Jurisdicción Social, sin reparar en el hecho de que, sin reconocer la existencia de un contrato de trabajo a las trabajadoras sexuales que se dediquen a la prostitución, difícilmente podrán acudir a esta vía para obtener la debida tutela de sus derechos ${ }^{29}$.

\footnotetext{
${ }^{25}$ Por todas, STSJ Galicia de 10 de noviembre de 2004 (Recurso de Suplicación no. 3598/2004).

${ }^{26}$ Entre otras, STSJ de Madrid de 18 febrero 2019 (Recurso de Suplicación no. 868/2018), o STSJ de Cataluña de 23 de diciembre de 2004 (Recurso de Suplicación no. 9446/2003).

27 STSJ de Cataluña de 17 de septiembre de 2003 (Recurso de Suplicación no. 3826/2003).

28 Por todas, la STS de 21 de diciembre de 2016 (Recurso de casación para la unificación de doctrina №. 1868/2015)

${ }^{29}$ Quizá por este motivo, la entrada que a la sentencia se realiza en el Diario La Ley se dice "El contrato es nulo y por tanto, no se puede accionar por despido pero sí por vulneración del derecho a la intimidad ante el orden civil"(Diario La Ley, No 9617, 21 de abril de 2020).
}

Revista del Laboratorio Iberoamericano para el Estudio Sociohistórico de las Sexualidades https://doi.org/10.46661/relies.4975 


\subsection{El derecho de sindicación en el ámbito de la prostitución}

El asociacionismo obrero ha constituido uno de los ejes sobre los que se ha construido el derecho del trabajo. Vía para la formación de una comunidad de intereses y de su presentación reivindicativa ante la sociedad y los poderes que la gobiernan, el derecho de sindicación de los trabajadores, junto los derechos que conlleva (negociación y conflicto) supone una herramienta eficaz para la defensa de los derechos de las personas representadas.

"El libre y real ejercicio del derecho de asociación, del derecho de sindicación, del derecho a la información $-y$, sobre todo, del verdadero derecho a ser escuchado por los poderes públicos, que hace que sus titulares puedan hacerse visibles y audibles en el propio proceso de construcción de los derechos-, junto con el derecho de crítica frente a leyes, reglamentos y decisiones, incluso judiciales, que puedan constituir, prima facie, vulneraciones de derechos fundamentales, constituye la expresión de aquello que identificamos como las garantías sociales de los derechos, imprescindibles para el mantenimiento de la democracia real y para asegurar la eficacia de los propios derechos, comenzando por los sociales" (Schwarz, 2019, p. 180).

La necesidad de organizarse para defender los propios derechos ha sido una constante en la historia del derecho del trabajo, que no se entendería sin el movimiento obrero. Esa realidad asociativa y reinvidicativa se ha materializado históricamente, pese a los obstáculos que hayan podido ir planteándose por parte de los poderes del Estado, ante la necesidad de mejorar las condiciones de vida y de trabajo. Así ha sucedido con las prostitutas, que vienen organizándose desde mediados de la década de los años setenta del siglo XX. De este modo, ya en 1973 la prostituta y activista feminista Margo St. James fundó, en la ciudad de San Francisco (EE.UU.), la asociación COYOTE (Cast Off Your Old and Tired Ethics) una entidad sin fines de lucro, entre cuyos objetivos no se encontraba abolir la prostitución, sino lograr el respeto de los derechos de las prostitutas (Heim, 2012). En Europa, fue en 1975 cuando a raíz de la ocupación de la iglesia de Saint-Nizier en Lyon por parte de un grupo de prostitutas, como una acción de denuncia de la política represiva de la policía francesa, se inició el movimiento asociativo de las prostitutas -hecho que dio pie al nacimiento al día internacional de las trabajadoras sexuales, que se celebra el 2 de junio-, un movimiento no exento de mofa y represión, así como desinterés por parte de la policía de velar por su seguridad (Mathieu, 1999, 478-480).

Esta forma de organización "sindical" de grupos excluidos de los tradicionales sindicatos legalmente constituidos no es exclusiva de la prostitución. Junto al de las trabajadoras del sexo, se puede dar cuenta de los "sindicatos" de manteros (sindicato popular de vendedores ambulantes ${ }^{30}$ ), de inquilinos ${ }^{31}$, el sindicato de mujeres cuidadoras $\sin$ papeles $^{32}$, o de los riders ${ }^{33}$, que han coordinado medidas de supervivencia ante la crisis de la COVID-19. La movilización de estos colectivos, habitualmente excluidos del juego político institucional, viene a reforzar la conclusión de que la representación y la acción colectiva constituyen una de las formas de expresión colectiva de los descontentos sociales, siendo que algunos de estos sindicatos contarían con el aval del Tribunal Constitucional ${ }^{34}$. Para el caso de otros, como el de prostitutas, quizá haya que esperar a dicho apoyo en forma de sentencia que reconozca su derecho de asociación.

En cualquier caso, la organización colectiva de las prostitutas mediante estructuras representativas, así como el ejercicio de acciones reivindicativas no resulta una tarea sencilla. Ello es así, ante todo, porque este colectivo no cuenta con el apoyo de buena parte de los sindicatos tradicionales que, al

\footnotetext{
${ }^{30}$ https://manteros.org/

${ }^{31} \mathrm{https}: / /$ sindicatdellogateres.org/

32 https://www.facebook.com/sindicatodecuidadorasinpapeles/

33 https://www.facebook.com/ridersxderechos/

${ }^{34}$ STC 236/2007, de 10 de diciembre, respecto de los extranjeros en situación irregular.
}

Revista del Laboratorio Iberoamericano para el Estudio Sociohistórico de las Sexualidades https://doi.org/10.46661/relies.4975 
adoptar una postura abolicionista/prohibicionista, les dan la espalda, o al no tener clara cuál es la postura a defender tampoco les ofrecen su apoyo ${ }^{35}$. Además, el colectivo de prostitutas carece de una tradición reivindicativa, o de organización en movimientos colectivos: porque muchas de ellas no quieren dejar el anonimato en el cual desempeñan su actividad, que realizan con absoluta discreción, para evitar que familiares o conocidos lleguen a tener conocimiento de la misma; porque en ocasiones se puede apreciar una falta de sentimiento identitario, al no darse un contacto entre ellas y primar la competitividad antes que la necesidad de defender sus intereses comunes (Pons $i$ Antón, 1990, p. 170); por el escarnio al que se han visto sometidas cuando han intentado hacer valer sus derechos; por las acusaciones constantes que se lanzan contra cualquiera que se mueva en reivindicación del colectivo, esgrimiendo contra estos sindicatos su escasa representatividad del colectivo, dada su escasa afiliación -sin tener en cuenta ni el contexto general de baja afiliación sindical, ni el contexto particular apenas expuesto que hace todavía más difícil contar con trabajadoras afiliadas-, o acusándolos de estar integrados por empresarios del sector, de buscar la defensa la industria de la prostitución. Nótese que esta última acusación no deja de ser una manifestación más de la actitud de descalificación mantenida por algunos sectores frente a todo aquel que defiende una postura contraria al abolicionismo, en una especie de argumento ad personam por el que descalificando al interlocutor se pretende hacer lo propio con el mensaje.

En este contexto, la organización sindical de las prostitutas es una labor ciertamente compleja. A pesar de ello, poco a poco han ganado presencia las organizaciones de prostitutas como consecuencia del fortalecimiento de las estructuras de relaciones sociales existentes entre ellas como consecuencia de los ataques a sus intereses. En definitiva, tales ataques han derivado en una mayor movilización de las prostitutas en defensa de sus derechos. Así ha ocurrido en España, donde la Organización sindical de Trabajadorxs Sexuales (OTRAS) surgió en 2018, como consecuencia "de la necesidad de garantías sociales y políticas de un grupo amplio de personas involucradas en un cambio profundo y necesario que deriva, entre otras cosas, del momento de convulsión ideológica mundial con el auge de las derechas radicales por un lado, y los feminismos, por otro" ${ }^{36}$. Identificándose como profesionales del sector económico del sexo, este sindicato se declara abolicionista de toda forma de explotación y defiende una postura pro-derechos.

Pero si la organización colectiva no resulta sencilla, tampoco lo resultan sus métodos de acción. Así se evidencia con la experiencia adquirida con las manifestaciones de prostitutas en Paris en el año 1972, cuando fueron objeto de señalamiento y hostigamiento por parte de la sociedad, por lo que, cuando decidieron movilizarse en la Francia de 1975 en defensa de unas condiciones dignas para desarrollo de su actividad, se decidieron por ocupar iglesias, en un tipo de acción seguido posteriormente por otros colectivos desfavorecidos, como los inmigrantes. Una forma de protesta que les evitaba la exposición pública que tanto rehusaban (Mathieu, 1999, pp. 483, 484).

\section{2.a. El derecho de asociación y sindicación de las prostitutas y sus empleadores visto por los tribunales laborales españoles}

En relación con el derecho de organización colectiva en el mundo de la prostitución, en el ámbito español, resulta imprescindible referirse a tres sentencias, dos de ellas relativas a la organización de

35 https://www.elsaltodiario.com/sindicatos/debate-otras-sindicato-prostitutas-contradicciones-ugt-ccoo-cgt-cnt. Solamente la Intersindical Alternativa de Cataluña se ha mostrado colaborativa con las demandas de las prostitutas, creando una sección sindical de trabajadoras sexuales. Cabe recordar que este sindicato ha sido el mismo que ha dado cobertura a los riders, cuya situación guarda similitud con la de las prostitutas por lo que se refiere a su dispersión geográfica y competitividad entre los trabajadores.

${ }^{36}$ https://www.sindicatootras.org/-que-decimos-.html

Revista del Laboratorio Iberoamericano para el Estudio Sociohistórico de las Sexualidades https://doi.org/10.46661/relies.4975 
los propietarios de clubs de alterne -SAN de 23 de diciembre de 2003 (sentencia no. 104/2003) sobre la organización Mesalina y la posterior STS de 27 noviembre 2004 (Recurso de Casación 18/2004), por la que se confirma la primera-, y una tercera relativa a la organización sindical -SAN de 19 de noviembre de 2018 (Recurso no. 258/2018) sobre el sindicato OTRAS-.

En el caso de las sentencias sobre el caso Mesalina, el conflicto arranca de la descripción, en los estatutos de la organización, de su objeto social, incluyéndose una referencia expresa a la prostitución. Ante esta circunstancia, la Dirección General de Trabajo requirió, para proceder al depósito y registro de los mismos, la supresión de dicha referencia. Ante el requerimiento efectuado, la asociación añadió dos párrafos, señalando el primero que "la referencia realizada en el párrafo anterior a la actividad de alterne y prostitución por cuenta propia se realiza exclusivamente para delimitar concretamente el ámbito sectorial de la asociación, y bajo ninguna circunstancia debe entenderse en el sentido de inducción, promoción, intermediación o cooperación, con estas actividades". Ante esta respuesta, y considerando la Dirección General de Trabajo que no se había procedido a subsanar el defecto observado ${ }^{37}$, se denegó el depósito de los mismos.

Recurrida la decisión, recayó en primera instancia la SAN de 23 de diciembre de 2003 en la que el Abogado del Estado argumentó, en primer término, que, "en nuestro ordenamiento jurídico, esta actividad no se encuentra regulada, estando únicamente tolerada". Además, objetó -por vez primera- el nombre de la asociación (Mesalina), considerando que pudiera ser discriminatorio por razón de género respecto de las mujeres, "pues de muchos es sabido el significado que Mesalina tiene en la lengua española". Este segundo motivo esgrimido para denegar la inscripción fue rechazado en la sentencia, tanto por ser la primera vez que se invocaba, privando de la oportunidad de subsanación, como por cuanto el mero uso de la "expresión (sic)" Mesalina no puede dar lugar a censura jurídica. Para ello debería emplearse "en un contexto y con un referente que lo impregne de un matiz semántico degradador o descalificador", sin que el uso del término Mesalina, en este caso, "resulte calificador o definidor de género o especie, sino identificado de persona concreta, en otras palabras, no es empleado como nombre común sino como nombre propio y no tiene sentido una interpretación autorreferente que lleve a hablar de acto de discriminación contra uno mismo" (FD 3).

Tras cuestionar el proceder de la Dirección General de Trabajo ${ }^{38}$, la sentencia reconoce el carácter extrajurídico de la calificación como "actividad tolerada" en relación con la prostitución, y considera que carece de todo sentido "condicionar el ejercicio de una actividad económica a que esté regulada, puesto que la constitución reconoce la libertad de empresa sin hacerla depender de la mayor o menor diligencia reguladora de los poderes públicos" 39 . Por todo ello, la sentencia ordenó formalizar la inscripción de la "Asociación Nacional de Empresarios Mesalina" (ASNEM) en el Registro de Asociaciones correspondiente.

En el posterior recurso de casación interpuesto por parte de la Dirección General de Trabajo, ésta alegaba que el objeto social de la asociación impedía su inscripción en el Registro de Asociaciones,

\footnotetext{
${ }^{37}$ Consideró la Dirección General de Trabajo que el párrafo añadido no constituye sino una declaración de principios propia de cualquier tipo de asociación, siendo que las asociaciones que persigan fines o utilicen medios tipificados como delitos, se declararán ilegales.

${ }^{38}$ Estima la sentencia que, más que aludir a vicios formales, la Dirección General entró a hacer valoraciones de alcance material, cuya vía impugnatoria sería la judicial más que la vía administrativa de subsanación de defectos formales.

${ }^{39}$ En cualquier caso, la sentencia reconoce que nos encontramos ante una actividad regulada, pues lo está en el Código Penal, que fija la frontera "no en el carácter altruista o remuneratorio del intercambio sexual, sino la libertad con que el mismo se presta. De este modo, la relación será o no antijurídica sólo en atención al consentimiento con que se presta el favor sexual"' (FD 5).
}

Revista del Laboratorio Iberoamericano para el Estudio Sociohistórico de las Sexualidades https://doi.org/10.46661/relies.4975 
"pues sus Estatutos conducirían de nuevo a una asociación que agrupa a quienes explotan la prostitución ajena, entendiendo que los objetivos a los que se dirige la asociación son puramente laborales, ya que las nociones 'negociación colectiva laboral', de 'conflicto colectivo de trabajo' e incluso la de 'diálogo social' se predican de relaciones laborales plenas, no de relaciones meramente mercantiles". Por consiguiente, concluye en sus argumentaciones, no cabe una referencia a la prostitución por cuenta propia en los estatutos, pues la misma se encuentra "en flagrante contradicción con el sentido mismo de lo pretendido por ellos, a saber, actuar como contraparte empresarial de quienes se dedican laboralmente al 'alterne'".

La STS de 27 noviembre 2004, por la que se resolvió el referido recurso, lo desestimó. El TS entiende que lo que debe examinarse en el asunto planteado es si la actividad mercantil consistente en la tenencia de hoteles destinados a dispensar productos o servicios a terceras personas ajenas al establecimiento que ejerzan el alterne o la prostitución por cuenta propia puede o no constituir el objeto de una asociación empresarial, siendo que éstas deben intervenir en las relaciones laborales, defendiendo los intereses económicos y profesionales que le son propios a través de la negociación colectiva laboral, el diálogo social, el planteamiento de conflictos colectivos de trabajo y la participación institucional en los organismos públicos de las Administraciones laborales. Pues bien, dado que las empresas que integran la Asociación Mesalina "son titulares de los establecimientos hosteleros de referencia, que por su propia naturaleza necesitan para su funcionamiento de personal laboral, como son los camareros, limpiadoras, etc.., y el 'alterne', en su caso, cuando la actividad sea laboral", el tribunal considera que existe legitimación de tales empresarios para asociarse y para intervenir, en cuantos problemas se deriven de las relaciones laborales que les conciernan.

De ambas sentencias cabe extraer las siguientes conclusiones: a) La prostitución es una actividad económica cuyo ejercicio no puede quedar condicionado a que esté regulado como consecuencia del reconocimiento de la libertad de empresa. b) Solamente es posible denegar validez jurídica a las realidades que están prohibidas por el ordenamiento jurídico. c) Las actividades "toleradas" no son actividades prohibidas. d) La prostitución por cuenta propia está admitida en nuestro ordenamiento jurídico. e) Los empresarios titulares de los locales donde se ejerce la prostitución intervienen en las relaciones laborales de sus empleados, entre los cuales se encuentra el alterne, cuando se ejerza con los criterios propios de la laboralidad.

La tercera de las sentencias que guarda relación con el derecho de asociación de las prostitutas es la de la SAN de 19 de noviembre de 2018, en la que se resuelve el recurso interpuesto por la Comisión para la investigación de malos tratos a mujeres en relaciób con el sindicato OTRAS. En los Estatutos de este sindicato se indicaba, como ámbito funcional, "las actividades relacionadas con el trabajo sexual en todas sus vertientes", siendo objeto de litigio que se incluyese, entre ellas, el ejercicio de la prostitución. De este modo, en el intento de conciliación previo al juicio, se ofreció el desistimiento de la demanda a cambio de precisar en los Estatutos que su ámbito funcional no incluía la prostitución, propuesta que fue rechazada. La Audiencia Nacional, en esta sentencia, sobre la que ya tuve la oportunidad de efectuar un rápido análisis (Fita Ortega, 2019), declaró la nulidad de los Estatutos del sindicato OTRAS, pero sin admitir la disolución del sindicato propuesta por el demandante, al haber acumulado indebidamente las acciones.

Argumentó la Audiencia Nacional, en esta sentencia, que el desarrollo de una actividad empresarial cuyo objeto sea la oferta de servicios sexuales prestados por terceras personas, contratadas al efecto, es una actividad ilícita, no resultando un objeto válido en el marco de un contrato de trabajo el ejercicio de la prostitución bajo el ámbito organicista y rector de un tercero. Desde este punto de partida, y valorando la negativa a excluir la prostitución por cuenta ajena del ámbito funcional de los estatutos del sindicato, los declara nulos, pues las consecuencias de su admisión resultarían totalmente contrarias al ordenamiento jurídico por cuanto que supondría:

Revista del Laboratorio Iberoamericano para el Estudio Sociohistórico de las Sexualidades https://doi.org/10.46661/relies.4975 
“a.- dar carácter laboral a una relación contractual con objeto ilícito;

b.- admitir que el proxenetismo... es una actividad empresarial lícita;

c.- admitir, a su vez, el derecho de los proxenetas a crear asociaciones patronales con las que negociar condiciones de trabajo y frente a las que se pudieran adoptar medidas de conflicto colectivo, posibilidad ésta que expresamente descarta la STS de 27-11-2004 ya referida;

d.- asumir que de forma colectiva la organización demandada y los proxenetas y sus asociaciones puedan negociar las condiciones en la que debe ser desarrollada la actividad de las personas empleadas en la prostitución, disponiendo para ello de forma colectiva, de un derecho de naturaleza personalísima como es la libertad sexual- entendiendo por tal el derecho de toda persona de decidir con qué persona determinada se quiere mantener una relación sexual, en qué momento y el tipo de práctica o prácticas que dicha relación debe consistir" (FD 7).

Como tuve la oportunidad de señalar en el comentario realizado a esta sentencia, destacar que en la interpretación que del derecho hacen los jueces pesan no solamente consideraciones de tipo jurídico, sino también otras de tipo extrajurídico, no supone realizar una gran revelación, ni produce una especial sorpresa, aunque ello suponga evidenciar que los interpretes de las normas se apartan de los cánones hermenéuticos marcados en el artículo tercero del Código Civil. Esta afirmación resulta patente en temas cuya situación jurídica es confusa. Se tiende aquí a emplear la indeterminación normativa como coartada para introducir argumentos jurídicos que no son sino una construcción voluntarista del derecho, dirigida a una suerte de activismo judicial que, en lugar de fundamentarse en la tutela de los derechos fundamentales reconocidos en los textos constitucionales, tiende a imponer una visión de las reglas que regulan los intereses en juego en un pleito conforme a las propias creencias o valores del juzgador. Todo ello aunque así se pueda ir en contra de obligaciones constitucionalmente como la de "promover las condiciones para que la libertad y la igualdad del individuo y de los grupos en que se integra sean reales y efectivas, así como de remover los obstáculos que impidan o dificulten su plenitud y facilitar la participación de todos los ciudadanos en la vida política, económica, cultural y social" (artículo 9.2 CE). Esto es, precisamente, lo que sucede con el reconocimiento de la prostitución como posible objeto de un contrato de trabajo y el consiguiente derecho de las trabajadoras que ejercen la prostitución a organizarse colectivamente.

Alega la Audiencia Nacional, en primer término, los compromisos internacionales asumidos por España. Se refiere, así, al Convenio para la Represión de la Trata de Personas y de la Prostitución Ajena, adoptado por la Asamblea General de Naciones Unidas en 2 de diciembre de 1949. Continúa argumentando que la asunción de tales compromisos internacionales tuvo reflejo en el texto del Código penal, en el que se tipifica como delito -en la actualidad en el artículo 187.1, párrafo $20_{-}$, la conducta de "quien se lucre explotando la prostitución de otra persona, aun con el consentimiento de la misma". Esta es una mentira intolerable en la argumentación jurídica efectuada por un tribunal en la resolución de un asunto. Si ya lo es cuando se utilizan de forma engañosa estos argumentos en los debates sobre prostitución, es absolutamente execrable su uso en un tribunal en sus resoluciones.

Del artículo 187.1 del Código Penal no se desprende, en absoluto, que la prostitución ejercida voluntariamente pueda ser considerada en todo caso como delito. Como recuerda la STS de 22 abril 2010 (rec. 506/2007), el Código Penal mantiene estrictamente la sanción para los actos de aprovechamiento o explotación llevados a cabo por terceros en relación con el ejercicio de la prostitución, pero eliminando la consideración delictiva de aquellas conductas de explotación que se pueden considerar de menor intensidad como el rufianismo (vivir en todo o en parte a expensas de las personas prostituidas) o el proxenetismo locativo (arrendamiento o cesión de locales para el ejercicio de la prostitución) En este mismo sentido, la SAN de 23 diciembre 2003 (rec. 168/2003) señalaba que "la relación pues no es antijurídica por razones causales (el chalaneo prestacional) o

Revista del Laboratorio Iberoamericano para el Estudio Sociohistórico de las Sexualidades https://doi.org/10.46661/relies.4975 
por el objeto de intercambio sino solo en atención al consentimiento con que se presta el favor sexual sea porque la capacidad del arrendador está limitada -menores o incapaces- sea porque su voluntad está viciada, en el supuesto de los capaces" (FD 5). Y así lo ha vuelto a recordar más recientemente, y antes de recaer la Sentencia de la Audiencia Nacional de 2019, la STS de 22 de marzo de 2018 (Recurso de Casación no. 10484/2017), en la que se indica que no cabe entender encuadrable en el delito tipificado en el artículo $187.1 \mathrm{CP}$ la conducta de quien ni compele ni coacciona al ejercicio de la prostitución, pese a que sí obtenga beneficio económico de ella, cuando es la prostituta quien ejerce voluntariamente esta actividad. Ni la doctrina penalista ni los tribunales de este orden jurisdiccional han avalado nunca interpretaciones como la señalada por la Audiencia Nacional, pues nunca han calificado como delictiva la conducta del "empresario" que se lucra de la prostitución ajena, contando con el consentimiento de la persona prostituida (Marín de Espinosa Ceballos, 2016, p. 1049). Por tanto, la afirmación formulada por los magistrados en su sentencia, o bien supone el desconocimiento del derecho o, lo que resulta igualmente grave, falta a la verdad en una resolución judicial.

El segundo argumento que esgrime la sentencia de la Audiencia Nacional para estimar la impugnación de los Estatutos del sindicato OTRAS consiste en sostener que no resulta posible, con arreglo a nuestro derecho, la celebración de contrato de trabajo cuyo objeto sea la prostitución por cuenta ajena, esto es, "un contrato en virtud del cual el trabajador asuma la obligación de mantener las relaciones sexuales que le indique el empresario, con las personas que este determine a cambio de una remuneración, concluyendo que el contrato que así se celebre deba reputarse nulo" (FD 5). El problema de esta artación estriba en la correcta determinación del objeto del contrato relativo a la prostitución. Ese objeto nunca podría pasar por el sometimiento de la trabajadora a las imposiciones de actividad sexual del empresario proxeneta, pues ello vulneraría gravemente la libertad sexual de la misma. El objeto consistiría en el ejercicio de la actividad sexual -cuya concreción corresponderá siempre a la trabajadora o trabajador- con quien la prestadora o prestador del servicio desee llevarlo a cabo, dentro de la esfera rectora y organicista del empresario manifestada en aspectos tales como, entre otros, el sometimiento a una jornada, a las indicaciones acerca de cómo vestir, así como a un eventual poder disciplinario del empresario que nunca podría sancionar la negativa de la trabajadora a querer mantener relaciones sexuales con algunos clientes o realizar ciertas prácticas, pues en otro caso se estaría vulnerando su libertad sexual ${ }^{40}$. De este modo, la subordinación en estos casos se vería matizada, de forma similar a como ocurre en otras relaciones laborales.

\section{2.b Una valoración al derecho de sindicación de las prostitutas desde la prohibición de discriminación y la universalidad de los derechos humanos}

Frente a estos argumentos cabe plantear otros en cuya virtud sí debería haberse admitido la validez de los estatutos del sindicato OTRAS y haber dado trámite a su depósito. En primer lugar, y por lo que se refiere a los compromisos internacionales adquiridos por España, cabría destacar, por una parte, que los que se suelen invocar no son directamente aplicables. Es lo que ocurre con el Convenio para la Represión de la Trata de Personas y de la Prostitución Ajena, citado en la SAN de 19 de noviembre de 2018 sobre el sindicato OTRAS que, además de desconocer las sentencias del

\footnotetext{
${ }^{40}$ Hace ya tiempo que el bien jurídico protegido en delitos como el antiguo delito de violación (hoy día agresiones sexuales) dejó de ser la honestidad, por lo que también en el caso de las prostitutas cualquier compulsión a mantener relaciones sexuales sería constitutiva de delito ("solo sí, es sí", es válido también en el caso de las prostitutas)
}

Revista del Laboratorio Iberoamericano para el Estudio Sociohistórico de las Sexualidades https://doi.org/10.46661/relies.4975 
Tribunal Supremo sobre el artículo 187 del Código Penal, desconoce igualmente la jurisprudencia del Tribunal Supremo sobre este Convenio ${ }^{41}$.

Por otra parte, con independencia de estos referentes normativos internacionales, debe tenerse en cuenta que la Constitución prima sobre los mismos en la jerarquía de fuentes por la que se rige nuestro ordenamiento jurídico. $Y$ existen tres preceptos de la norma constitucional que exigen el reconocimiento de los derechos sindicales a las prostitutas. El primero de ellos es el ya comentado artículo 9.2 de la CE. En relación con él cabe traer a colación las conclusiones de Naciones Unidas a través de su programa sobre VIH y SIDA, en el que señala que dificultar la organización colectiva de las trabajadoras sexuales supone uno de los mayores efectos negativos de la criminalización del trabajo sexual (UNAIDS, 2012 Annexo 1,5).

El segundo es el artículo 14 de la CE, que prohíbe la discriminación y exige la igualdad de trato ante la ley. En efecto, si la prostitución es una actividad económica que no se encuentra prohibida en nuestro ordenamiento jurídico, ni ejercida por cuenta propia, ni por cuenta ajena cuando medie la voluntad de la prostituta, y cuyo ejercicio no puede quedar -en virtud de la libertad de empresacondicionado a que esté regulado; si, además, el ejercicio de la prostitución por cuenta propia está reconocido expresamente por los tribunales laborales $\mathrm{y}$, por consiguiente, las prostitutas autónomas económicamente dependientes podrían constituir asociaciones de interés profesional, o afiliarse a un sindicato; si en estas circunstancias las prostitutas por cuenta ajena sufren trato desfavorable, se produce una quiebra tanto del principio de igualdad como del de no discriminación. $Y$ es que esa diferencia de trato no deriva de un régimen legal diferenciado en virtud de alguna justificación razonable, sino que, precisamente, se produce como consecuencia de la ausencia del reconocimiento de la legalidad de la actividad cuando se ejerce por cuenta ajena por parte de los tribunales (laborales, hay que destacar, pues no es así en otros órdenes jurisdiccionales). La ley trata por igual a la prostitución por cuenta propia como a la prostitución por cuenta ajena, siendo la interpretación de los tribunales laborales la que quiebra estos derechos fundamentales.

Por último, tenemos el reconocimiento del derecho a la libertad sindical recogido en el artículo 28.1 de la Constitución. Procede recordar, a este respecto, lo señalado por el Tribunal Constitucional en su sentencia 236/2007, de 7 de noviembre, relativa al recurso de inconstitucionalidad planteado en relación con, entre otras cuestiones, la redacción dada al artículo 11.1 de la Ley Orgánica 4/2000, de 11 de enero, sobre derechos y libertades de los extranjeros en España y su integración social, en virtud de la LO 8/2000. Tras la reforma operada por ésta última, el artículo 11.1 de la LO 4/2000, pasaba a reconocer el derecho de sindicación, o afiliación a una asociación profesional, de los ciudadanos extranjeros, en las mismas condiciones que los trabajadores españoles, pudiendo ejercer estos derechos únicamente cuando obtuviesen "autorización de estancia o residencia en España", constituyendo este último inciso el motivo que suscitó las dudas de constitucionalidad de este precepto.

La STC 236/2007 declara la inconstitucionalidad del referido precepto invocando disposiciones de carácter internacional, así como la interpretación del artículo 28.1 efectuada por el propio Tribunal Constitucional. De este modo, se argumenta que, siguiendo el criterio interpretativo ex artículo 10.2 $\mathrm{CE}$, ha de tenerse en cuenta el reconocimiento del derecho de asociación y sindicación de toda

\footnotetext{
${ }^{41}$ La STS (Sala de lo Contencioso-Administrativo) de 22 de abril de 2010 (recurso de Casación no. 506/2007) consideró que, si bien dicho Convenio (junto con la Convención sobre la eliminación de todas las formas de discriminación contra la mujer a la que también se refiere) carece de un carácter meramente programático, pues forma parte del sistema de fuentes del ordenamiento jurídico, la aplicación directa de estas normas viene obstaculizada por su carácter no selfexecuting de sus disposiciones, requiriendo de un ulterior desarrollo legal y reglamentario que represente la voluntad de nuestro Estado.
}

Revista del Laboratorio Iberoamericano para el Estudio Sociohistórico de las Sexualidades https://doi.org/10.46661/relies.4975 
persona previsto en la normativa internacional (artículo 23 de la Declaración Universal de los Derechos Humanos; el artículo 22 PIDCP; el artículo 8 PIDESC; el artículo 11.1 CEDH; la Carta Social Europea o los Convenios no. 87 y no. 98 de la OIT). Por ello, se considera que el artículo 28.1 de la CE reconoce la titularidad del derecho de libertad sindical "a 'todos' los trabajadores en su caracterización material, y no jurídico-formal, y a 'todos' los sindicatos", de tal manera que

no resulta constitucionalmente admisible la exigencia de la situación de legalidad en España para su ejercicio por parte de los trabajadores extranjeros, aunque lo sea para la celebración válida de su contrato de trabajo y, en consecuencia, para la obtención de la condición jurídico-formal de trabajador[...]. La concepción según la cual el derecho de libertad sindical se ejercería exclusivamente por quienes ostentan la condición de trabajador en sentido legal, es decir, por quienes 'sean sujetos de una relación laboral'[...], no se corresponde con la titularidad del derecho fundamental, ejercitable, entre otras finalidades posibles en la defensa de los intereses de los trabajadores, para llegar a ostentar tal condición jurídico-formal (FJ 9).

Por estos motivos, la sentencia declara la inconstitucionalidad del artículo 11.1 de la Ley Orgánica 4/2000, de 11 de enero, por ser contrario al artículo $28.1 \mathrm{CE}$, si bien solamente por lo que se refiere al derecho a sindicarse libremente, pero no al derecho a afiliarse a una organización profesional.

La fundamentación de esta sentencia resulta plenamente aplicable al caso de la prostitución, pues no siendo sujetos de una relación laboral, resulta que son igualmente titulares del derecho fundamental de libertad sindical ${ }^{42}$, "ejercitable, entre otras finalidades posibles en la defensa de los intereses de los trabajadores, para llegar a ostentar tal condición jurídico-formal” (FJ 9). Tampoco resulta compatible con el derecho a la libertad sindical "la limitación consiguiente que deriva para el derecho de los sindicatos de defender y promover los intereses de estos trabajadores" (FJ 9). En todo caso, la limitación prevista en la LO 4/2000 respecto del derecho de libertad sindical de los extranjeros no se contempla en ninguna norma reguladora de la libertad sindical, por cuanto, en aplicación de la Ley Orgánica de Libertad Sindical, el derecho de las prostitutas a la libertad sindical está integrado no solamente por el de derecho de afiliación, sino también por el derecho a la constitución de sindicatos.

Análoga conclusión se ha alcanzado por Tribunales Constitucionales de otros países, como el caso de Sudáfrica, país donde este tribunal, en sentencia de 26 de mayo de 1999 (SANDU v Minister of Defense, Case CCT 27/98), extendió el concepto de "trabajador" más allá de los límites derivados de la existencia de una relación laboral. Haciéndose eco de esta sentencia, la resolución del Labour Appeal Court (Johannesburgo) en el asunto Kylie $v$ Commission for Conciliation Mediation and Arbitration and Others (Case No.: CA10/08) reconoce que siendo "trabajadoras" a pesar de que la actividad que ejercen es ilegal en su país, las prostitutas tienen derecho a la libertad sindical, sea para constituir sindicatos o afiliarse a uno, de modo que solamente podría negarse su inscripción en el correspondiente registro, si la finalidad del sindicato constituyese la promover la comisión de un delito (apartado 58).

$\mathrm{Si}$, en el caso en el que la prostitución fuese ilegal, como en Sudáfrica, esta circunstancia no podría privar de derechos fundamentales, como la dignidad, menos todavía se comprende que, en una situación de alegalidad de la prostitución, los tribunales laborales se empeñen en privar a las prostitutas de aquellos que la Constitución les reconoce.

42 En este sentido, Miñarro (2019) y Molina Navarrete (2019)

Revista del Laboratorio Iberoamericano para el Estudio Sociohistórico de las Sexualidades https://doi.org/10.46661/relies.4975 


\section{Bibliografía}

Acton, W. (1870): Prostitution, considered in its moral, social and sanitary aspects, Londres: John Churchill and sons.

Alonso Olea, M. (1971): "Sobre la realidad subyacente al Derecho del Trabajo", Revista de Trabajo, 2, pp. 148-161.

Beltrán, E. (2011): “En los márgenes del derecho antidiscriminatorio: prostitución y derechos de las mujeres", Anales de la Cátedra Francisco Suárez, 45. Disponible en https://revistaseug.ugr.es/index.php/acfs/article/view/524. Último acceso el 8 de agosto de 2020.

Brufao, P. (2008): Prostitución y políticas públicas: entre la reglamentación, la legalización y la abolición, Estudios de progreso. Fundación alternativas. Disponible en http://www.fundacionalternativas.org/public/storage/estudios documentos archivos/xmlimportjPZHaj.pdf. Último acceso el 8 de agosto de 2020.

De la Villa, L.E. (1969): “En torno al concepto del Derecho español del Trabajo”, Revista de Trabajo, 26, pp. 103-118.

Fita Ortega, F. (2007): "El trabajo sexual en la doctrina judicial española" en Prostitución y trata: marco jurídico y régimen de derechos (coord. por Rosario Serra Cristóbal), Valencia: Tirant lo Blanch, pp. 203-254.

Fita Ortega, F. (2009): "La prostitución: posible objeto de contrato de trabajo como una manifestación más del trabajo sexual" Revista de Derecho Social, 47, pp. 91-108.

Fita Ortega, F. (2019): "Acerca de la nulidad del trabajo sexual como ámbito funcional de un sindicato" Diario La Ley, 9344 (revista on-line).

Lacordaire, J-B. H. (1872): Oeuvres du R.P.Henri-Dominique Lacordaire de l'ordre des prèresprêcheurs Tomo IV. gallica.bnf.fr / Bibliothèque nationale de France.

Mac, J. \& Smith, M. (2018): Revolting prostitutes. The fight for sex workers' rights, Londres, New York: Verso.

Marín de Espinosa Ceballos, E.B. (2016): "Lucrarse explotando la prostitución ajena, aún con el consentimiento: ¿cabe el reconocimiento de la prostitución consentida como una relación laboral?". Estudios de Derecho Penal. Homenaje al profesor Miguel Bajo. Madrid: Editorial Universitaria Ramón Areces, pp. 1045-1064.

Mathieu, L. (1999): “Une mobilisation improbable: l'occupation de l'égise Saint-Nizier par les prostituées lyonnaises", Revue française de sociologíe, XL-3, pp. 475-499.

Mccrudden \& Prechal (2009): The Concepts of Equality and Non-Discrimination in Europe: A practical approach, Comisión Europea. Noviembre.

Miñarro, M. (2019): “La libertad sindical de «todos» no alcanza a «las OTRAS»: la Audiencia Nacional confunde titularidad del derecho de libertad sindical con legalización de la prostitución. Revista de Trabajo y Seguridad Social. CEF, 430, pp. 143-148.

Molina Navarrete, C. (2019): "El concepto-tipo jurídico-material de trabajador a efectos de la libertad sindical: razones normativas de las "trabajadoras del sexo» para su disfrute", Revista Española de Derecho del Trabajo, 217, pp. 205-252.

Nubiola, J. y J. Bernal (2012): “Pornografía” en Diccionario General de Derecho Canónico, Volumen VI. Aranzadi, Thomson-Reuters. Pamplona.

Revista del Laboratorio Iberoamericano para el Estudio Sociohistórico de las Sexualidades https://doi.org/10.46661/relies.4975 
Perera, P.S. (2019): "Sobre la libertad de ejercicio en la prostitución: tres argumentos y una estrategia abolicionistas a debate", 17/2019. En https://recyt.fecyt.es/index.php/encrucijadas/article/view/79184. Último acceso el 8 agosto de 2020.

Peris, M.C. (1990): "Prostitución valenciana en la segunda mitad del siglo XIV", Revista d'historia medieval, 1, pp. 179-199.

Pons i Antón, I.M. (1990): La cara oculta de la luna. Condiciones de vida de las prostitutas en Asturias. Tesis doctoral presentada en el Departament de Sociologia i Metodologia de les Ciències Socials de la Universitat de Barcelona. En http://hdl.handle.net/2445/43016. Último acceso el 8 agosto de 2020.

Schwarz, R. (2019): Derechos Sociales. Fundamentación y garantías, Editora Unoesc.

Seña, J.F. (1992): “Acerca de la pornografía”, Revista del Centro de Estudios Constitucionales, II (enero-abril), pp. 219-237.

UNAIDS (2012): Guidance Note on HIV and Sex Work. En https://www.unaids.org/en/resources/documents/2012/20120402 UNAIDS-guidance-note-HIVsex-work. Último acceso el 8 agosto de 2020. 